\title{
CONTADOR-PARTIDOR: ¿CONTAR Y PARTIR?
}

\author{
José Manuel Fernández Hierro
}

Sumario: 1. La figura del contador-partidor. 2. Derecho comparado. 3. Ordenamiento español. 4. Albaceas y contadores. 5. La reforma del Código Civil. 6. Nombramiento. 7. Funciones. 7.1. Partición de la herencia. 7.2. Formación del inventario. 7.3. Valoración. 7.4. Interpretación del testamento. 7.5. Facultad de ordenar suplementos en metálico. 7.6. Adjudicación para pago de deudas. 7.7. Liquidación de la sociedad de gananciales. 7.8. Arbitrar las diferencias. 8. Efectos. 8.1. Ejercicio de la partición. 8.2. Forma. 8.3. Efectos jurídicos. 8.4. Impugnación.

\section{La figura del contador-partidor}

La figura del contador-partidor ha sido en general poco estudiada por la doctrina después de la reforma del artículo 1.057 del Código Civil ${ }^{1}$.

La normativa legal se encuentra desperdigada entre el Código Civil y la Ley de Enjuiciamiento Civil, siendo fundamental a este respecto el artículo 1.057 del Código Civil, el cual fue reformado en mayo de 1981.

Pero también la Ley de Enjuiciamiento Civil se refiere al ContadorPartidor en los artículos 1.070 y siguientes al referirse al juicio de testamentaría e indirectamente al abintestato.

1 Sobre este particular, véase además de las obras generales:

CAMY SÁNCHEZ-CAÑETE, B.: «Contador-partidor y personas a quienes válidamente puede adjudicar bienes», en Revista de Derecho Privado, 1968, p. 311.

Ruiz ARTAcho, S.: «Partición de herencia por comisario», en Revista Crítica de Derecho Inmobiliario, 1952, p. 241.

SÁENZ DE SANTA MARÍA TINTURE, I.: «Notas sobre los albaceas y contadores-partidores», en Anuario de Derecho Civil, VI-2, 1953, p. 385.

TortosA, A.: «Contador-partidor dativo. Nota al art. 1.057 del Código Civil después de la reforma de 13 de mayo de 1981. Escritura de nombramiento», en Boletín Informativo Colegio Notarial de Granada, n. ${ }^{\circ}$ 13, enero 1982, p. 163. 
Sin embargo ninguno de los preceptos citados contienen una definición del contador partidor - lo cual debe entenderse lógico y correctopero ni siquiera la enumeración clara de sus funciones.

\section{Derecho comparado}

La figura del contador-partidor podría tal vez encuadrarse dentro de las que en Derecho comparado aparecen como ejecutores testamentarios: así sucede con el B.G.B. n. ${ }^{\circ} 2.197$ el cual señala que el ejecutor, entre otras funciones tiene la de efectuar las participaciones entre los coherederos a quienes oirá (n. $\left.{ }^{\circ} 2.204\right)$, y con el Derecho italiano según el cual en su artículo 706 el ejecutor testamentario tiene la posibilidad de que el testador le faculte, siempre que no sea heredero o legatario, a la distribución de bienes entre los herederos.

El Código Civil suizo en su artículo 518 señala las facultades del ejecutor testamentario, entre ellas la de proceder a la división conforme a lo que señala el testador o la Ley. También el Derecho inglés señala la posibilidad de que los ejecutores testamentarios (personal representatives) puedan proceder a la adjudicación del testamento entre los herederos en virtud de la Administration of States Act 1.925, s. 43.

En cambio el Derecho francés no contiene tales facultades para los ejecutores testamentarios, si bien pueden proceder a la venta del mobiliario de acuerdo con el artículo 1.031 del Código Napoleón que señala:

«Les exécuteurs testamentaires feront apposer les scellés, s'il y a des héritiers mineurs, majeurs en tutelle ou absents.

Ils feront faire, en présence de l'héritier présomptif, ou lui dûment appelé, l'ínventaire des biens de la succession.

Ils provoqueront la vente du mobilier, à défaut de deniers suffisants pour acquitter les legs.

Ils veilleront à ce que le testament soit exécuté; et ils pourront, en cas de contestation sur son exécution, intervenir pour en soutenir la validité.

Ils devront, á l'expiration de l'année du décès du testateur, rendre compte de leur gestion.»

\section{Ordenamiento español}

En nuestro ordenamiento jurídico la situación se complica por diversos motivos:

1. ${ }^{\circ}$ Porque existen diversas clases de ejecutores testamentarios: los albaceas y los contadores partidores son dos figuras jurídicamen- 
te distintas y que en otros ordenamientos jurídicos están agrupadas en una sola.

2. ${ }^{\circ}$ Porque la figura del contador-partidor no solamente surge de las sucesiones, sino también en los supuestos de disolución de la sociedad de gananciales.

3. ${ }^{\circ}$ Porque existen diversas clases de contadores partidores (dirimente o de parte) y también diferencias en cuanto a su nombramiento (testamento, voluntad de los coherederos o designación en procedimiento judicial).

\section{Albaceas y contadores}

El ordenamiento jurídico español contiene, dentro de lo que genéricamente se denomina como «testamentarios», distintas funciones.

Por un lado, la de los albaceas o propiamente ejecutores testamentarios; por otro, la de los contadores-partidores llamados también comisarios, denominación que contiene el artículo 1.057 del Código Civil y que se realiza por ejemplo en la Resolución de la Dirección General de los Registros y del Notariado de 27 de diciembre de 1982 entre otras 2 .

El albacea, según Puig Ferriol ${ }^{3}$, es la persona designada por el causante con el objeto de ejecutar y hacer ejecutar el interés ajeno, las disposiciones de última voluntad de acuerdo con lo expresado en el testamento.

La diferencia entre albacea y contador-partidor de acuerdo con tal definición parece evidente:

a) Por su nombramiento, en cuanto que la figura de albacea es nombrada por el testador o no existe, mientras que la del contadorpartidor puede ser nombrada no sólo por el testador sino también por los herederos.

b) Por su ámbito, el albacea sólo interviene en los supuestos de herencia, mientras que el contador-partidor puede hacerlo también para la disolución de la sociedad de gananciales.

c) Por sus funciones, las del contador-partidor se limitan a repartir la herencia - aunque la etimología de la palabra parece hacer

2 Algún sector doctrinal ha entendido que la figura del comisario es distinta de la del contador-partidor propugnando una triología de funciones: albacea, contador-partidor y comisario. En contra de tal interpretación SÁENZ DE SANTA MARÍA, obra citada, p. 387. Tengamos en cuenta la posibilidad además de la existencia del administrador de la herencia diferente de la de los anteriores, con lo cual sí se configura la trilogía antes indicada.

3 El albaceazgo, en Ed. Boch, Barcelona 1967, p. 34. 
referencia también a la formación del inventario (contar $=$ contador) - la realidad es que en diversas hipótesis el inventario precede al nombramiento del contador-partidor y sus funciones son fundamentalmente las de partir y no las de contar, aunque sí las de valorar (y solamente las de contar en el supuesto de que haya posturas contrapuestas en orden a la inclusión de bienes en el inventario).

d) Los contadores pueden ser uno o varios mancomunados o solidarios.

Si nada se indica serán mancomunados ex art. 895 del Código Civil, además de la pluralidad — uno designado por cada parte— que prevé la Ley de Enjuiciamiento Civil.

Notemos además que para la figura del albacea se ha recurrido fundamentalmente a la teoría del mandato o alternativamente a la de la representación, entendiendo que el albacea es un representante del testador o de los herederos, postura que no cabe defender cuando se trata del contador-partidor, y que algunas sentencias del Tribunal Supremo han entendido que a las funciones del comisario le son aplicables, mutatis mutandis, las del albaceazgo ${ }^{4}$, e incluso algún fallo parece asimilar tácitamente ambas funciones.

\section{La reforma del Código Civil}

La reforma operada en mayo de 1981 ha sido importante dada la redacción antigua del artículo 1.057 del Código Civil ${ }^{5}$ y su confrontación con el texto actual, y ha introducido la figura del llamado por la doctrina «contador partidor dativo».

De la comparación de ambos textos resulta:

1. ${ }^{\circ}$ Que la nueva redacción previene la posibilidad del contador-partidor por los trámites sumarios del nombramiento de perito, posibilidad que no contenía el artículo primitivo.

2. ${ }^{\circ}$ Se establecen unos trámites para su nombramiento, en sede de jurisdicción voluntaria, que evidentemente antes no podían existir.

${ }^{4}$ Sentencia 27 de abril de 1978, Ar. 1.458. En cuanto a la homologación de ambas funciones, Sentencia 7 de enero de 1942, Ar. 4.

5 Art. 1.057. El testador podrá encomendar por acto inter vivos o mortis causa para después de su muerte la simple facultad de hacer la partición a cualquiera persona que no sea uno de los coherederos.

Lo dispuesto en este artículo y en el anterior se observará aunque ente los coherederos haya alguno de menor edad o sujeto a tutela; pero el comisario deberá en este caso inventariar los bienes de la herencia, con citación de los coherederos, acreedores y legatarios. 
3. ${ }^{\circ}$ Se fija que la participación realizada requerirá la aprobación de todos los herederos y legatarios o aprobación judicial.

Por el contrario, lo que no cambia es la indicación de que aun cuando haya menores o sujetos a tutela valdrá lo dispuesto en este artículo y en el anterior, pero en ese caso el inventario de los bienes de la herencia los deberá hacer el contador-partidor con citación de los coherederos, acreedores y legatarios.

\section{Nombramiento}

En cuanto a su nombramiento, la reforma del artículo 1.057 del Código Civil $^{6}$, señala dos posibilidades distintas.

Vamos a ver tales alternativas:

1. ${ }^{\circ}$ La de que el testador señale a cualquier persona la facultad de partir sus bienes, con el solo límite de que no sea uno de los herederos.

Tanto Roca Sastre ${ }^{7}$ como Sáenz de Santa María ${ }^{8}$ señalan la necesidad de la existencia de un testamento para la existencia de un contador-partidor.

Entiendo que tal observación es correcta, siempre que no se refiera al contador-partidor dativo introducido por la reforma del artículo $1.057 \mathrm{del}$ Código Civil en el que específicamente se admite la figura del contadorpartidor no habiendo testamento, o del juicio de abintestato en el que está previsto en función de la remisión del artículo 1.001 de la Ley de Enjuiciamiento Civil al contenido de los artículos 1.070 y concordantes de la propia Ley.

2. ${ }^{\circ}$ La posibilidad de que el juez, a petición de herederos o legatarios, designe un contador-partidor por las reglas que contiene la Ley de Enjuiciamiento Civil para la designación de peritos.

6 Art. 1.057. El testador podrá encomendar por acto «inter vivos»o «mortis causa» para después de su muerte la simple facultad de hacer la partición a cualquier persona que no sea uno de los coherederos.

No habiendo testamento, contador-partidor en él designado o vacante el cargo, el juez, a petición de herederos y legatarios que representen, al menos, el 50\% del haber hereditario, y con citación de los demás interesados, si su domicilio fuere conocido, podrá nombrar un contador-partidor dativo, según las reglas que la Ley de Enjuiciamiento Civil establece para la designación de peritos. La partición así realizada requerirá aprobación judicial, salvo confirmación expresa de todos los herederos y legatarios.

Lo dispuesto en este artículo y en el anterior se observará aunque entre los coherederos haya alguno de menor edad o sujeto a tutela; pero el Comisario deberá en este caso inventariar los bienes de la herencia con citación de los coherederos, acreedores y legatarios.

7 Derecho Hipotecario, tomo III, Barcelona 1968, p. 844.

8 Obra citada, p. 408. 
Para ello hace falta:

a) Que lo pidan los herederos o legatarios que representen al menos el $50 \%$ del caudal hereditario.

El Código Civil no hace distinción entre herederos y legatarios con lo cual bastará que en conjunto se supere dicho $50 \%$.

b) Que se hayan citado previamente los demás interesados.

El artículo 1.057-2 del Código Civil señala que para que proceda el nombramiento de contador-partidor es necesario que concurran las circunstancias que él previene, esto es, por:

a) No existir testamento.

b) Porque en el testamento no estuviera el cargo de contador-partidor.

c) Porque dicho cargo estuviera vacante, bien fuera por haber transcurrido el plazo para efectuar la partición sin que el contador-partidor lo hiciera, o bien por renuncia de éste o por cualquier otro motivo que tiene la consecuencia de que, en cualquiera de tales hipótesis, se puede designar contador-partidor dativo.

Ahora bien, tales formas de nombramiento no son las únicas, ya que existen otras cuales son el nombramiento unánime de todos los herederos y legatarios sin necesidad de la intervención judicial, bien directamente, bien a través de sus representantes legales efectuado extrajudicialmente; el nombramiento efectuado en la junta que para el juicio de testamentaria señala el artículo 1.068 de la Ley de Enjuiciamiento Civil y para el de abintestato el mismo artículo en relación al 1.001, ambos de la Ley procesal.

Por tanto el nombramiento del contador-partidor podrá ser hecho:

1. ${ }^{\circ}$ Por el testador.

2. ${ }^{\circ}$ Por los interesados de común acuerdo.

3. ${ }^{\circ}$ Por el juez, mediante el procedimiento que señala el artículo 1.057 del Código Civil.

4. ${ }^{\circ}$ En juicio voluntario de testamentaría.

Conviene resaltar que la Ley de Enjuiciamiento Civil previene la posibilidad de nombramiento en el juicio de testamentaría $-\mathrm{y}$ por extensión en el de abintestato- de dos clases de contadores-partidores, el dirimente y los designados previamente que pueden serlo de común acuerdo de las partes o cada uno el suyo (artículo 1.071 de la Ley de Enjuiciamiento Civil).

Aunque el hecho de que fueran nombrados previamente los contadores partidores por las partes de común acuerdo no empece la posible existencia ulterior del contador-partidor, no es lo habitual, ni lo lógico: si las 
partes pueden ponerse de acuerdo en el nombramiento de uno o varios contadores-partidores lo normal, en evitación de gastos y repeticiones inútiles, es que se pase directamente al nombramiento del contador-partidor dirimente, y si no que previamente cada parte designe un contadorpartidor.

A este respecto el Tribunal Supremo ha entendido nula la partición realizada en que se hubiera incurrido previamente en defecto de citación de los respectivos interesados ${ }^{9}$ aunque la sentencia de 23 de diciembre de $1976^{10}$ considera que la omisión de la citación de las partes no es determinante de la nulidad absoluta, aunque sí de la relativa o anulabilidad:

«Que según conocida por la reiterada doctrina jurisprudencia, la partición realizada por Comisario nombrado expresamente por el testador equivale a la hecha por éste, equiparación entre una y otra clase de partición, que encuentra su única excepción en el caso de que entre los coherederos haya alguno de menor edad o sujeto a tutela, en cuyo supuesto, el artículo 1.057, párrafo 2. ${ }^{\circ}$, del Código Civil, impone al Comisario el deber de inventariar los bienes de la herencia, con citación de los coherederos, acreedores y legatarios, medida de precaución tomada por el legislador en el exclusivo interés de estas personas, siendo manifiesto que la Ley reputa necesaria tal citación para la formalización del inventario, el cual es la base fundamental sobre la que descansan las operaciones particionales, citación cuya falta u omisión no vicia de nulidad radical o absoluta las operaciones particionales realizadas, pero sí de su nulidad relativa o anulabilidad, la cual únicamente puede ser reclamada por aquellos en cuyo favor o beneficio se ha establecido la garantía, esto es, por los coherederos, acreedores y legatarios.»

A este respecto conviene señalar que la jurisprudencia ha entendido que el nombramiento de contador-partidor efectuado por el causante no es válido para atribuir los bienes de la sociedad conyugal, por lo cual deberá para tal función intervenir el cónyuge superstite ${ }^{11}$.

En principio no hay limitaciones para el nombramiento de contador partidor, con la excepción de que no podrá ser ninguno de los herederos; ni siquiera el ser legatario de cuota alícuota ha sido considerado por la Resolución de la Dirección General de los Registros y el Notariado de 30 de junio de $1956^{12}$ como suficiente motivo para impedir al legatario ser al mismo tiempo contador-partidor.

9 Sentencias 26 de noviembre de 1955, Ar. 3.588 y 5 de octubre de 1973, Ar. 3.557.

10 Ar. 5.578. Idéntica S. 17 de diciembre de 1988, Ar. 9.475.

11 Sentencia 22 de agosto de 1914, C.J., tomo 131, n. ${ }^{\circ} 51$.

12 Resolución criticada por DíEz PiCAZo y Gullón en Instituciones de Derecho Civil, vol. II, Ed. Tecnos, Madrid 1995, p. 801. En idéntico sentido, esto es, en el de no aceptar que el legatario sea también contador-partidor se pronuncia EsCOBAR DE LA RIVA, «Partición por comisario», en Revista Crítica de Derecho Inmobiliario, 1940, p. 392. 
¿Cabría no obstante mantener que las causas de recusación de los peritos que contiene el artículo 621 de la Ley de Enjuiciamiento Civil? En mi opinión habría que distinguir:

1. ${ }^{\circ}$ Si el nombramiento fuera efectuado por el testador o por todos los interesados de común acuerdo sólo cabría la recusación por hechos que fueran conocidos con posterioridad al nombramiento: la situación no es la misma en caso de contienda judicial que en el supuesto de un contador-partidor designado extrajudicialmente y más aún si es elegido por el testador el cual es lógico que haya indicado a alguien de su confianza que le haya prestado sus servicios $y$, con mucha frecuencia algún familiar, sin que estos extremos deban ser en ninguna hipótesis causa de recusación salvo que el nombramiento fuera efectuado de otra forma y en este caso la situación de relación fuera del contador-partidor exclusivamente con uno o varios de los interesados en la herencia.

$2 .^{\circ}$ En el supuesto en que más aplicable parece la institución de la recusación es en el del contador-partidor dativo que previene el artículo 1.057-2. ${ }^{\circ}$ del Código Civil al no haber sido designado directamente por todos los interesados ni por el testador.

En cualquier caso el Código Civil no señala causas de recusación, por lo que habría que, para el supuesto del artículo 1.057-2. ${ }^{\circ}$ emplear analógicamente la de las causas de recusación de peritos, salvo la hipótesis del contador-partidor dativo en la cual el llamamiento a las normas de designación de perito hace que puedan aplicarse, también, las reglas para su recusación. Cuando se trata de contadores-partidores señala claramente la referencia del artículo 1.073 a los artículos 616 a 625 todos ellos de la Ley de Enjuiciamiento Civil la posibilidad de recusación contenida en el artículo 621 de la misma.

Es de notar que el Tribunal Supremo en la sentencia de 24 de mayo de $1954^{13}$ ha entendido que los notarios podían ser designados contadores-partidores en los testamentos que otorgaban:

«Que, conforme al artículo 29 de la Ley Orgánica del Notariado, lo dispuesto en los artículos 22 y 27 de la misma Ley, en cuanto a la prohibición impuesta a los notarios para autorizar contratos que contengan disposición a su favor y a la nulidad de los instrumentos por ellos autorizados en que aparezcan disposiciones de esa clase, no es aplicable a los testamentos y demás disposiciones mortis causa, en las cuales, según el citado artículo 29, regirán la ley o leyes especiales del caso, o sea, en la actualidad, el Código Civil, a cuyo texto no podría sobreponerse según declaró la sentencia de

13 Ar. 1.325 . 
este Tribunal de 5 de diciembre de 1921, el artículo 126 del Reglamento notarial de 9 de abril de 1917, entonces en vigor, que no permitía a los notarios autorizar documentos en que se les nombrara contadores de herencias, y, sin duda, obedeciendo a este criterio jurisprudencial, desapareció esa prohibición en reglamentos posteriores, y el hoy vigente de 2 de junio de 1944 en su artículo 139 expresamente exceptúa de la prohibición de autorizar actos jurídicos que contengan disposiciones a favor del notario la de testamentos en que se les nombre albaceas o contadores-partidores.»

En cambio cuando nos referimos al contador-partidor dirimente señalado en el artículo 1.070 de la Ley de Enjuiciamiento Civil debe ser necesario que concurra en él la condición de letrado, esto es, abogado en ejercicio, por indicación expresa de dicho artículo.

Cuando se trate de la disolución de la sociedad de gananciales el contador-partidor deberá ser designado como tal por los propios cónyuges, ya que sería aplicable subsidiariamente las reglas del juicio de testamentaría, ex artículo 1.410 según ha señalado el Tribunal Supremo en sentencia de 20 de junio de $1987^{14}$.

\section{Funciones}

¿Cuáles son las funciones del contador-partidor?

Ninguno de los preceptos legales aplicables, ni del Código Civil ni de la Ley de Enjuiciamiento Civil contiene una enumeración de sus funciones.

Se ha dicho que su función es muy clara y que incluso su propio nombre lo indica: contar y partir ${ }^{15}$, pero realmente tal simplificación parece excesiva, ya que el contador-partidor ni siempre tiene que contar ni en todos los casos debe hacer exclusivamente tales funciones.

El cargo de contador-partidor es, como señala Roca Sastre ${ }^{16}$, personalísimo, temporal y puede ser retribuido:

«La función de contador-partidor no es susceptible de ser delegada en otra persona, porque el testador lo designa por la confianza que le merecen sus dotes personales o condiciones de idoneidad. Así lo entienden las resoluciones de 12 de noviembre de 1895, 22 de enero de 1898, 25 de marzo de 1906, 30 de junio de 1914, 15 de julio de 1943, y otras.

El cargo de contador-partidor es temporal, por cuya razón se rige por las normas del Código Civil sobre el albaceazgo, y prevalentemente por

14 Ar. 4.539. Cuando no sea letrado podrá auxiliarse de los técnicos que entienda necesario. Así Lledó YaGüE: Derecho de sucesiones, vol. IV, Universidad de Deusto, Bilbao, 1993, p. 93, aunque no, evidentemente, el contador partidor dativo (Ibidem, p. 108).

15 Así Roca Sastre, obra citada, p. 851.

16 Obra citada, p. 845. 
la voluntad del testador. El artículo 1.057 nada dice sobre el particular. Por ello, de no establecer el testador plazo especial para la partición, regirá el plazo general de un año que establece el artículo 904 del Código Civil, el que será prorrogable por el tiempo que fijan los artículos 905 y siguientes del Código. Transcurrido el plazo fijado sin haber efectuado la partición, se entiende tácitamente que éste renuncia sus facultades de tal, correspondiendo entonces a los herederos practicar la partición. Las sentencias de $1 .^{\circ}$ de junio de 1926 y 22 de febrero de 1929, y la Resolución de 13 de noviembre de 1903, se pronuncian en este sentido.

Puede ser retribuido el cargo de contador-partidor por disponerlo así el testador que lo haya designado, el cual deberá fijar la remuneración, según resulta del artículo 908 del Código Civil.

Como subsidiariamente el cargo de contador-partidor se regula por las normas del Código Civil relativas a los albaceas, en cuanto les sean aplicables, regirán estas normas. Por ello, como el cargo de contador-partidor puede recaer en una persona o en varias, simultánea o sucesivamente, a título de sustitutos, y cuando los contadores-partidores sean dos o más serán de aplicación los artículos 895 y 897 del Código Civil. Así lo entiende la Sentencia de 5 de febrero de 1908.»

Notemos que el contador-partidor dirimente, que deberá ser letrado, y también el contador-partidor dativo, en el supuesto de serlo, podrán calcular su remuneración no con arreglo a lo que señale el Código Civil sino de acuerdo a los honorarios profesionales: en realidad se trata de un trabajo más propio de la actividad de abogado y con matices, para el que lo realiza, que le aproximan al arbitraje.

El Tribunal Supremo en su Sentencia de 6 de abril de $1962^{17}$ señala que:

«Entre las operaciones particionales hay que distinguir las formalizadas por el comisario, de naturaleza unilateral y las que se realizan por todos los herederos que tienen naturaleza contractual, puesto que las primeras, las facultades conferidas al comisario por voluntad del testador, le autorizan como juez imparcial para realizar todas las operaciones que tiendan a la liquidación de la herencia, división y adjudicación de los bienes, y, por tanto, la partición que realice con sujeción a las prescripciones legales producirá todos sus efectos y a ella se deberán acomodar los herederos en tanto no perjudique los derechos legitimarios.»

De acuerdo con la misma, las funciones conferidas al testador, son todas las que tiendan a la liquidación, división y adjudicación de los bienes, funciones amplias, aunque no precisas y que podían suponer una colisión a la que tienen atribuida los albaceas.

Vamos a ir señalando sucesivamente algunas de estas funciones:

17 Ar. 1.712 . 


\subsection{Partición de la herencia}

La función más clara y más evidente del contador-partidor y aquella que justifica su existencia es la de partir la herencia.

Ninguna duda hay al respecto de que tiene facultades para hacerlo: la controversia está en otras facultades que pueden ser complementarias o previas de la de partir.

Así el contador-partidor en modo alguno es representante legal de la herencia ni puede contratar en nombre de la misma.

Tampoco puede atribuirse ninguna de las funciones que para el albacea contienen los artículos 902 y 903 del Código Civil ${ }^{18}$.

Los contadores-partidores por tanto ni son representantes de la herencia, ni pueden disponer de los bienes hereditarios, siendo su misión mucho más concreta.

Enumera a este respecto como operaciones propias del contador-partidor Roca Sastre ${ }^{19}$ las siguientes:

«La simple facultad de hacer la partición comprende la práctica, bajo las bases o supuestos de hecho y de derecho, las operaciones siguientes:

El inventario: determinar el activo y pasivo hereditario.

El avalúo: valorar tales elementos.

La liquidación: deducir del valor del activo el del pasivo, y después, no antes, agregar el valor de lo colacionable. cipe.

La fijación de haberes: determinar el haber hereditario de cada partí-

ades de los albaceas, tendrán las siguientes:

1. ${ }^{\mathrm{a}}$ Disponer y pagar los sufragios y el funeral del testador con arreglo a lo dispuesto por él en el testamento; y, en su defecto, según la costumbre del pueblo.

2. ${ }^{a}$ Satisfacer los legados que consistan en metálico, con el conocimiento y beneplácito del heredero.

3. ${ }^{a}$ Vigilar sobre la ejecución de todo lo demás ordenado en el testamento, y sostener, siendo justo, su validez en juicio y fuera de él.

4. ${ }^{a}$ Tomar las precauciones necesarias para la conservación y custodia de los bienes, con intervención de los herederos presentes.

Art. 903 del Código Civil. Si no hubiere en la herencia dinero bastante para el pago de funerales y legados, y los herederos no lo aportaren de lo suyo, promoverán los albaceas la venta de los bienes muebles; y, no alcanzando éstos, la de los inmuebles, con intervención de los herederos.

Si estuviere interesado en la herencia algún menor, ausente, corporación o establecimiento público la venta de los bienes se hará con las formalidades prevenidas por las leyes para tales casos.

El carácter del contador como no responsable de la herencia resulta de las sentencias de 28 de abril de 1987 (C.J. tomo 81, 2..$^{a}$ parte, n. ${ }^{\circ} 44$ ) y 25 de enero de 1956, Ar. 262.

19 Obra citada, p. 847. 
La división de bienes: hacer de los bienes del activo hereditario neto los lotes correspondientes en bienes de la misma especie y calidad.

La adjudicación de bienes: atribuir o asignar a cada coheredero (y en su caso al legatario o legatarios de parte alícuotas), en pago de su haber, los bienes hereditarios que correspondan, sin perjuicio que, de haber deudas y cargas hereditarias, se formen las correspondientes hijuelas de los bienes destinados a ello.»

Observemos no obstante que el testador puede conceder al contadorpartidor además de las facultades propias de su cargo otras como las de poder apoderarse de los bienes hereditarios y entregarlos a los adjudicatarios; igualmente el testador puede restar al contador las facultades que desee.

Los albaceas son los ejecutores testamentarios universales mientras que los contadores-partidores tienen una misión puntual, la de partir la herencia con las operaciones previas o inherentes a la misma ${ }^{20}$.

Todo ello sin perjuicio de que el contador partidor deba acatar las normas contenidas en el testamento o la voluntad racionalmente previsible del testador y de la Ley.

\subsection{Formación del inventario}

Antes de dividir los bienes hay que inventariarlos para tener constancia de aquellos a los que se extiende el caudal hereditario o el de la sociedad de gananciales en su caso: por eso es la operación previa que señalan en sus artículos 1.065 y 1.066 de la Ley de Enjuiciamiento Civil los cuales determinan la forma de hacer el inventario y relacionan a éste como previo a la elaboración del cuaderno particional.

La Resolución de la Dirección General de los Registros y del Notariado de fecha 6 de marzo de 1993 señala cómo la partición de herencia exige la previa determinación del caudal a dividir mediante riguroso inventario.

Sin embargo, el problema no es tan sencillo de solución como parece: en primer lugar, porque tal normativa no es aplicable al contador-partidor dativo del artículo 1.057 del Código Civil, y en segundo lugar, porque, a pesar de lo indicado en la Ley de Enjuiciamiento Civil, podría darse el supuesto de que, por impugnaciones o desacuerdos en la formación del inventario, éste no estuviera resuelto a la hora de efectuar el correspondiente cuaderno particional.

20 Así Roca SAStRE: obra citada, p. 851. 
En efecto, los artículos 1.065, 1.066 y 1.067 de la Ley de Enjuiciamiento Civil señalan las normas sobre formación del inventario pero no relatan lo que sucede cuando hubiera discrepancia en los bienes a incluir ni los métodos para hacerlos constar.

La sentencia de 24 de febrero de $1993^{21}$ se inclina porque la inclusión o no de determinados bienes en el cuaderno particional se efectúe en un incidente del juicio de testamentaría indicando:

«... el hecho de que la Sentencia 3-5-1976 de la Sala de lo Civil de la Audiencia Territorial de Las Palmas fuera dictada en un incidente de exclusión de bienes del inventario pertinente en la liquidación de la sociedad de gananciales y que no tuviera acceso a la casación, ello no obsta a configurar sus pronunciamientos firmes por tanto con plena efectividad como cosa juzgada (art. 1.252 del Código Civil) toda vez que reúne todos sus requisitos subjetivos, objetivos y causales y además recaídos en proceso, aunque incidental, adecuado al objeto del debate ya que lo era en realidad incidente de una ejecución de sentencia principal. Por ello decae este motivo.»

En cambio la Sentencia de 14 de julio de 1994 señala como vía hábil la del juicio ordinario declarativo, independientemente del juicio de testamentaría y aceptándolo como propio para ventilar los problemas de la inclusión o no de determinados bienes en el caudal hereditario.

Es más, señala como misiones del juicio declarativo oportuno las de fijación de las cuotas correspondientes a cada heredero, determinación del patrimonio a dividir, e incluso, la realización de las operaciones divisorias, por lo que, en buena lógica, cabe entonces preguntarse qué finalidad tendría entonces la función del contador-partidor (e incluso en supuestos extremos) la de los juicios de testamentaría y abintestato.

La Sentencia de 5 de julio de $1994^{22}$ se inclina, en cambio, por la vía del juicio de testamentaría como cauce adecuado para resolver las cuestiones derivadas de la inclusión o exclusión de determinados bienes dentro del cuaderno particional:

«D) Las divergencias pueden suscitarse y resolverse sin necesidad de plantear cuestiones procesales incidentales relativas a la inclusión o exclusión de bienes, puesto que según el artículo 1.077 las particiones contendrán: $1 .^{\circ}$ relación de bienes que en concepto de cada uno "formen el caudal partible", y 2. el "avalúo de todos los comprendidos en esa relación".

En consecuencia, las relaciones de bienes pueden ser discrepantes y quedar como punto a decidir posteriormente por el dirimente, o pueden dar lugar a juicios declarativos cuando los titulares dominicales de los 
bienes los insten sin esperar a la decisión del dirimente, que efectivamente será siempre susceptible de impugnación (arts. 1.088 y concordantes).

E) La práctica judicial, más por la inercia de los antecedentes históricos que con base en la realidad legislativa vigente, y sin apoyo en los propósitos de la Ley de Enjuiciamiento Civil, ha tolerado los llamados incidentes de inclusión y exclusión de bienes, que han llegado incluso a esta Sala de Casación dando lugar a decisiones sin plantearse nunca el problema de la legalidad de estas demandas, su cauce procesal y las consecuencias de la tramitación en el desarrollo normal de los juicios de testamentaría. Que existen sentencias de esta Sala dictadas en resolución de incidentes de exclusión de bienes no impide que se exponga el verdadero propósito del legislador de 1881 en materia de procesos sucesorios.

F) La normativa anterior en la Ley de Enjuiciamiento Civil de 1855 no señalaba a las testamentarías y abintestatos una tramitación sujeta a reglas específicas, y la falta de ordenación legal provocó la inexistencia de criterios unitarios así como complicaciones económicas y retrasos que aconsejaron al legislador de 1855 intentar acabar con los abusos, tomar medidas rigurosas de tramitación y evitar las dilaciones que no sean absolutamente necesarias; así lo expresaba la Exposición de Motivos.

La Ley de 1881 siguió con buen criterio la "poda de incidentes" y supresión de dilaciones inútiles, y a cumplir dicho propósito lleva la interpretación dada al artículo 1.077, la cual permite afirmar que la Ley vigente no autoriza retrasos derivados de los incidentes de inclusión o exclusión de bienes en los inventarios. Basta para obtener esta conclusión con volver a recordar lo anteriormente dicho y tratar de responder a la pregunta sobre cuál es el número de incidentes que se pueden plantear, simultánea o sucesivamente, las instancias y casación que corresponde permitirles y si es compatible la enorme dilación de los procedimientos con la obtención de tutela judicial efectiva con ese cauce procesal.

G) Incuestionablemente, cuando en un inventario se incluyan bienes que pertenecen a otro dueño o no se incluyen los que, perteneciendo al común, los posee un coheredero o un tercero, pueden los que se crean con derecho a reivindicar o pedir mera declaración de dominio. En definitiva, hacer valer su derecho, y entonces será el juicio declarativo el que colateralmente y sin paralizar la testamentaría servirá para decidir la cuestión dando lugar en su día o a partición complementaria de bienes (art. 1.079 del Código Civil) o a la rectificación correspondiente a la exclusión de bienes.

H) No fue este el camino seguido por la testamentaría de la que procede este recurso, que fue iniciada en 1985, fue paralizada por la demanda incidental, hasta que recayó sentencia firme de la Audiencia de Burgos en 1988, tras la cual, sin acudir a casación, prosiguió hasta la partición del dirimente, que tuvo en cuenta la sentencia dictada.

La sentencia que anuló lo dispuesto en la escritura respecto a la cesión de bienes y prestación de alimentos, produce cosa juzgada material y no cabe plantear cuestión sobre lo mismo (aspecto negativo de la cosa 
juzgada), y todos los procesos posteriores en que se involucren tales bienes han de respetar lo decidido por la sentencia (aspecto positivo), y esto es lo que hizo el contador dirimente, tener como cuestión resuelta que los bienes formaban parte del caudal partible.

I) En conclusión, no deben favorecerse los incidentes paralizadores; el cauce adecuado para excluir bienes del juicio de testamentaría es el juicio declarativo correspondiente, y la decisión produce cosa juzgada entre las partes. Pero cosa juzgada también ha producido la sentencia dictada en proceso incidental, porque la fuerza decisoria no se pierde aunque, siguiendo la práctica forense, se sustanciara por la vía incidental, porque sabido es que bajo el nombre de incidentes está el juicio declarativo especial, que por ministerio de la Ley se ventila por el cauce de los artículos 741 y siguientes. Que incidentes propiamente dichos son los que cumplen los requisitos de los artículos 742, 744 y 745, pero que deben los jueces repeler de oficio los que no reúnan los requisitos legales para su calificación de cuestión relacionada con el asunto principal y que exijan una resolución independiente, previa o no. Y la sentencia que recaiga en dichos incidentes produce igualmente fuerza de cosa juzgada cuando no cabe contra ellos ningún recurso. Es por ello desacertada la cita de los artículos 741 y 745 a los efectos del recurso de casación, y también la cita de los artículos 1.068 y 1.088 de la Ley de Enjuiciamiento Civil, que lo único que hacen es permitir la impugnación de las particiones cuando no se cumplan las reglas legales de la misma.

Que el juicio de testamentaría tenga la naturaleza de jurisdicción voluntaria no impide que en él queden resueltas definitivamente las cuestiones hereditarias o que se confirmen tras la impugnación de las particiones en juicio declarativo como el presente cuando la impugnación no tiene otro apoyo que negar la eficacia de una resolución judicial firme. Por todo ello el motivo decae.»

En el amplio resumen transcrito de la sentencia se nos calibra la importancia de ésta en cuanto a que haga un estudio histórico de los medios existentes para solventar las discrepancias en orden a la formación del inventario y a que exponga las soluciones prácticas que entiende admisibles.

La sentencia transcrita no se decide por una vía unívoca porque:

a) Entiende que las relaciones de bienes pueden ser discrepantes y que pueden quedar al sometimiento del contador-partidor dirimente y en su caso a la formación de juicios de impugnación de dicho cuaderno particional.

b) Admite e incluso opta como vía adecuada por la posibilidad de la existencia de un juicio declarativo para pedir la inclusión o la exclusión de los bienes del inventario, independientemente de la anterior. 
c) La posibilidad de incidentes que, la sentencia glosada en principio rechaza como elementos paralizadores y perturbadores, no quedan excluidos tajantemente.

En cualquier caso señala que el juicio de testamentaría produce la excepción de cosa juzgada, aunque sea de jurisdicción voluntaria.

Pero la sentencia comentada deja al menos abiertas dos vías distintas: la de la inclusión por el contador-partidor dirimente de determinados bienes en el cuaderno particional y la impugnación en su caso, o la de los juicios declarativos de reivindicación o de declaración de dominio, admitiendo en principio ambos. Lo que parece en cambio que no debe ser admisible y que podría esgrimirse contra el segundo planteamiento la exención de litis pendencia es, la doble vía de la impugnación del cuaderno particional y del juicio declarativo.

Ahora bien, en el orden práctico si se produce la impugnación ¿qué hace el contador partidor? Las alternativas serían varias:

a) No efectuar la partición pendiente de la resolución en el incidente o en el juicio declarativo correspondiente de la inclusión o no de bienes en el testamento.

b) Entrar a estudiar las diversas alternativas planteadas sobre la inclusión o no en el inventario de determinados bienes tomando una postura al respecto, con la salvedad de que si alguien no estuviera de acuerdo pueda proceder ulteriormente a la impugnación del cuaderno particional.

c) Hacer el cuaderno particional como si las reclamaciones contra el mismo no hubieran tenido lugar y, en su caso, si éstas prosperaran proceder luego a la realización de un nuevo cuaderno particional.

La primera alternativa, que desde luego es la más aséptica para el contador-partidor, tiene el inconveniente de diferir ad calendae grecae la resolución de los problemas planteados: para los supuestos de que no hubiera impugnación o que la misma no prosperara tiene por el contrario la ventaja de que el cuaderno particional ya está redactado y terminado; mientras que la última, en el supuesto de que prosperara la impugnación, puede ofrecer aún una mayor dilación, puesto que hace falta un nuevo cuaderno particional, el cual a su vez puede ser objeto de nuevas impugnaciones.

En aras de la economía procesal y de la rapidez, estimo, como solución preferible, siempre que haya datos como para poder tomar una resolución, que el contador-partidor optara por solucionar en el cuaderno particional las dudas sobre el inventario y que, en su caso, se impugnara el cuaderno particional mediante el procedimiento judicial correspondiente. 
Eso no quiere decir que cualquiera de los otros métodos no sean válidos de acuerdo con la jurisprudencia transcrita y la Sentencia de 14 de julio recalca como la práctica judicial ha admitido los distintos medios o vías de impugnación, por lo que puede entenderse que todos ellos son válidos y que en definitiva serán las partes las que tengan que optar por uno u otro camino, en función de la resolución que también tome el contador-partidor y, en su caso, el juzgado. Ahora bien, todo ello se refiere a los supuestos de que el cuaderno particional se ha hecho previamente en el procedimiento judicial de acuerdo con los artículos 1.065 y 1.066 de la Ley de Enjuiciamiento Civil.

No es ocioso observar, sin embargo, que la actuación del contadorpartidor dirimente de acuerdo a la literalidad del artículo 1.078 de la Ley de Enjuiciamiento Civil puede limitar la función a formular aquellas operaciones en que hubiere desacuerdo, sin mayores atribuciones, lo que parece chocar con la interpretación amplia que la transcrita Sentencia de 8 de julio de 1994 le otorga.

Cosa distinta sucede cuando el contador-partidor ha sido designado por el testador o por común acuerdo de las partes al margen del procedimiento judicial: en tal hipótesis será él quien tenga que efectuar el inventario como primer paso de la elaboración del cuaderno particional.

\subsection{Valoración}

¿Puede el contador-partidor valorar los bienes de la herencia?

El artículo 1.077 de la Ley de Enjuiciamiento Civil lo señala respecto a los contadores-partidores previamente designados por las partes, pero no respecto al contador-partidor dirimente, e incluso alguna sentencia antigua del Tribunal Supremo parece negarle tal facultad insistiendo en que el contador-partidor está limitado a resumir los puntos en que las partes estuvieren conformes y formular con arreglo a derecho las operaciones divisorias en las que hubiera desacuerdo ${ }^{23}$.

Dentro de tales facultades la doctrina entiende que puede valorar y satisfacer la legítima sin reservas y apreciar la colación ${ }^{24}$ extremos lógicos ya que difícilmente puede hacer la partición sin satisfacer las legítimas y reservas, puesto que todas las citadas operaciones son parte de la partición.

No obstante la Sentencia de 2 de marzo de $1959^{25}$ señala que cuando en el testamento se le confiera a los contadores-partidores las más amplias

\footnotetext{
23 Sentencia 20 de diciembre de 1916, C.J., tomo 138, n. 145.

24 Por todos, Albaladejo y Díaz Alabart: obra citada, p. 239.

25 Ar. 1.089.
} 
facultades para practicar todas las operaciones de testamentaría y resolver las incidencias y asuntos que con ella se relacionan, su contenido excede de los del mero contador-partidor y tienen facultades de resolver todas las incidencias de la partición, entre ellas la fijación de las reservas, con determinación específica de los bienes reservables, por lo que, a sensu contrario, de tal jurisprudencia podría deducirse que tales facultades no las tiene el contador-partidor a quien en el título de la partición no se le han conferido.

En cualquier caso uno de los posibles motivos de oposición al cuaderno particional es que los legitimarios demuestren que la actuación del contador partidor perjudica las legítimas.

En el artículo 1.057 del Código Civil nada señala, si bien las mismas facultades deben entenderse respecto al contador-partidor dativo.

\subsection{Interpretación del testamento}

Subraya Roca Sastre ${ }^{26}$ cómo el contador puede interpretar el testamento cuando es necesario en orden al mejor desenvolvimiento de su función:

«Es generalmente admitido que el testador puede conceder específicamente al contador-partidor facultades interpretativas en orden a la partición, pero independientemente de ello estas facultades de interpretación fluyen naturalmente de su cometido particional, ya que el mismo tiene que hacer la partición, sin que pueda impedir ésta las dudas que surjan, las que deberá resolver, de suerte que cuando la voluntad del testador permita varias interpretaciones, el contador-partidor debe adoptar la que crea más legal y procedente. Así resulta de las resoluciones de 4 de diciembre de 1905, 29 de abril de 1913, 30 de enero de 1915, 9 de enero de 1918, 12 de diciembre de 1927, 15 de julio de 1943, 28 de marzo de 1944, 28 de abril de 1945, 18 de diciembre de 1951, 26 de marzo de 1952, etcétera.

Sin embargo, el contador-partidor debe adaptarse a las disposiciones del testamento y acatar las reglas de partición fijadas por el testador, de modo que su partición podría impugnarse si se diera el supuesto del artículo 1.075 del Código Civil, o sea si apareciere o racionalmente pudiera presumirse que la voluntad del testador fue otra de la que la partición refleja o presupone. Así resulta de las sentencias de 23 de noviembre de 1899, 5 de febrero de 1908, 11 de diciembre de 1913, 9 de enero de 1918, 22 de febrero de 1929, 18 de mayo de 1933, 10 de enero de 1934, 21 de noviembre de 1939, 9 de junio de 1952 y 8 de marzo de 1954, y resoluciones de 5 de octubre de 1893, 18 de mayo de 1900, 11 de setiembre de 1907, 29 de enero de 1908, 12 de diciembre de 1912, 29 de abril de 1913, 28 de abril de 1945, 18 de diciembre de 1951 y 11 de febrero de 1952.

26 Obra citada, p. 851 y sig. 
El contador-partidor, en sus funciones particionales, debe ajustarse naturalmente a la ley; así debe acatar las leyes prohibitivas (Sentencia de 11 de febrero de 1952), ha de respetar las legítimas (Resolución de 18 de diciembre de 1951, entre otras) y conforme hemos visto tiene que cumplir las reglas legales de la partición que establecen los artículos $1.061 \mathrm{y}$ 1.062 del Código.»

La posibilidad de que el albacea interprete el testamento es lugar común entre nuestra doctrina jurídica ${ }^{27}$ señalando a este respecto Albaladejo y Silvia Díaz Alabart ${ }^{28}$ que la alternativa se plantea entre conceder tales atribuciones al contador-partidor o que lo haga una persona ajena, entendiendo preferible la primera de las soluciones:

«Puesto que el contador debe partir, una de dos: o le toca aceptar, y aplicarla a la partición, la interpretación que competa a otro, sea quien sea, dar al testamento, o es al propio contador al que corresponde interpretarlo en lo que sea preciso para llevar a la práctica la partición.

Esta segunda es la posición que en principio adopta nuestro Derecho, en el bien entendido de que no es que pertenezca al contador la facultad de interpretar el testamento en todo, sino que sólo le pertenece, como facultad instrumental, en lo que sea preciso interpretarlo para partir, si es que la facultad de interpretar el testamento completamente o en lo que toca a la partición, no se ha concedido a otro.

Siendo el contador un albacea encargado del aspecto de ejecución de la voluntad del testador que consiste en partir, le compete como a todo albacea, sin necesidad de que le haya sido concedida una especial facultad de interpretación, la de interpretar lo que del testamento atañe a su encargo. Aparte de eso, el testador puede otorgar expresamente al contador la facultad de interpretar y ordenar que se acate el significado que él dé en el caso que sea.»

Efectivamente parece indubitable que para resolver la partición en los puntos oscuros o contradictorios del testamento habrá que interpretar éste, porque aquélla vendrá en función de la solución de los problemas del testamento: entiendo coherente que quien va hacer la partición sea la misma persona que siente los principios adecuados para efectuarla, a salvo la posibilidad de impugnación judicial de la misma.

Por su parte la jurisprudencia del Tribunal Supremo en Sentencia de 28 de junio de $1956^{29}$, entre otras señala la facultad del contador-partidor

27 Por todos, VAllet de Goytisolo, en «Facultades de los contadores-partidores para interpretar el testamento», Anuario de Derecho Civil, 1965, p. 227 y sig.

28 Comentarios al Código Civil y compilaciones forales, tomo XXIV, vol. II, p. 228. Dicho texto es el más extenso y completo después de la modificación del artículo 1.057 del Código Civil.

29 Ar. 3.002 . 
de interpretar el testamento, facultad que quedará incólume mientras no sea impugnada judicialmente su interpretación. Así la Sentencia de 18 de abril de $1985^{30}$ indica:

«Tiene declarado esta Sala, en su Sentencia de 28 de junio de 1956, que tales personas, como ejecutores testamentarios con amplias facultades, son de las más autorizadas para descubrir la verdadera voluntad del testador.»

¿Habrá que otorgar la misma facultad al contador-partidor dativo o al que es designado en el juicio de testamentaría?: pienso que sí y que ninguna distinción cabe al efecto por el hecho de que no fuera el testador el que designara el contador-partidor.

Ahora bien, la facultad del contador-partidor está sometida a la posible acción de los coherederos, y serán, en definitiva, los jueces y tribunales los que puedan decir la última palabra cuando se formulara oposición a las operaciones del contador-partidor dirimente, ex-artículo 1.085 de la Ley de Enjuiciamiento Civil; aunque lo que queda claro es que entre tanto no se impugne la intervención del contador-partidor dirimente queda revestida de una presunción de legitimidad que le otorga el artículo 1.083 de la Ley de Enjuiciamiento Civil ${ }^{31}$.

Notemos que la facultad de impugnación, según el Tribunal Supremo, no queda limitada a irregularidades procesales, sino que por el contrario concede de la manera más amplia, para quien no esté de acuerdo con la actuación del contador-partidor pueda impugnarla ${ }^{32}$.

Como señalan Albadalejo García y Díaz Alabart ${ }^{33}$, lo que la jurisprudencia del Tribunal Supremo significa es que la partición del contador se supone que contiene una interpretación correcta del testamento, y causa un estado de derecho hasta ser impugnada victoriosamente ante los tribunales, aún cuando no se pretende que prevalezca si es desacertada.

Ahora bien no comparto la crítica que hacen los autores últimamente citados a la presunción de legalidad y acierto de la actuación del contador-partidor cuando es rechazado por un organismo público como el Registro de la Propiedad: en mi opinión el favor testamenti debe extenderse a la partición efectuada legítimamente y la interpretación dada por el contador-partidor que se supone es ajeno a los herederos e

30 Ar. 1.771.

31 Aún cuando la Sentencia de 3 de diciembre de 1928 (C.J. 186, n. ${ }^{\circ} 81$ ) mantiene que la falta de oposición en el juicio de abintestato no indica conformidad con la partición y consiguientemente que no pueda promoverse después el juicio declarativo correspondiente.

32 Sentencia 8 de julio de 1992, Ar. 6.267.

33 Obra citada, p. 230 y sig. 
intereres de ésta, por lo que debe prevalecer sobre las interpretaciones que le dan las partes, e incluso sobre un tercero, que puede criticarlo exclusivamente desde el punto de vista del purismo jurídico, pero sin significar que la partición esté mal hecha, ya que de lo contrario contribuiría, otorgando un premio innecesario, a la litigiosidad posible de los herederos.

¿Qué sucede en la interpretación del testamento cuando el mismo choca con la Ley? Lacruz Verdejo y Sancho Rebullida ${ }^{34}$ señalan que la declaración de la ilicitud o no del testamento corresponde a los tribunales y no al contador-partidor. Por su parte Albadalejo y Díaz Alabart ${ }^{35}$ propugnan el que el contador-partidor debe acatar el testamento en el contenido del mismo que solamente sea dudosamente ilegal, y que en lo claramente ilegal su declaración corresponderá a los tribunales y no al comisario: tal opinión tiene el inconveniente de que fuerza la necesidad de un juicio para hacer valer la ilegalidad del testamento.

En cuanto a la jurisprudencia la Sentencia de 22 de abril de $1967^{36}$ manifiesta que el albacea debe asumir la obligación de acuerdo con lo que disponga la Ley; mientras que las sentencias de 11 de febrero de $1952^{37}$ y 24 de febrero de $1968^{38}$ señalan que los contadores-partidores están obligados a respetar la voluntad del testamento, pero nunca de un modo ciego y automático, sino ajustándose siempre a lo dispuesto en la Ley, y subsanando, en ese sentido los defectos u omisiones de las disposiciones de última voluntad.

\subsection{Facultad de ordenar suplementos en metálico}

¿Puede el contador-partidor ordenar suplementos en metálico?

El problema es importante y frecuente: pensemos sin ir más lejos en el supuesto en que en la masa hereditaria se encuentre un único bien inmueble existiendo dos herederos.

Pero hay que partir del principio contenido en el artículo 1.061 del Código Civil que señala la necesidad de adjudicar a todos los coherederos cosas de la misma naturaleza, calidad o especie, complementado por el artículo 1.062 que puntualiza cómo, cuando la cosa sea indivisible o desmerezca mucho por su indivisión, podrá adjudicarse a uno a cambio de abonar a los otros el exceso en dinero.

\footnotetext{
34 Elemento de Derecho Civil, tomo V, «Derecho de sucesiones», Barcelona 1981, p. 154.

35 Obra citada, p. 263.

36 Ar. 2.027.

37 Ar. 284.

38 Ar. 1.213.
} 
También hay que tener en cuenta el artículo 841 del Código Civil que indica que el contador-partidor expresamente facultado por el testador - $y$ por supuesto éste- puede adjudicar alguno de los bienes hereditarios a cualquiera de los hijos de los descendientes, ordenando que se pague en metálico la porción hereditaria de los otros legitimarios, facultad que le hace extensible al contador-partidor dativo del 1.057 del Código Civil; debiéndose también observar el contenido del artículo 1.056-2 del Código Civil que señala que el padre que en interés de su familia quiera conservar indiviso una explotación agrícola, industrial o fabril puede mantenerla disponiendo que se satisfaga en metálico su legítima a los demás hijos.

De la conjunción de los preceptos reseñados y de las limitaciones que resultan de los artículos 842 y siguientes del Código Civil podemos resumir la situación en los siguientes términos:

a) La norma es que el contador-partidor debe entregar a cada heredero bienes de la misma especie y calidad (siempre que sea posible), y por tanto no deberá entregar un bien a uno solo de ellos con la obligación de pagar en metálico a los demás (art. 1.061).

b) La excepción genérica constituirá los supuestos en que uno de los bienes sea indivisible (art. 1.062).

c) Otra excepción específica la constituye el de la explotación agrícola, industrial o fabril que el testador, en quien concurra además la circunstancia de ser padre de familia que explota en interés de la misma tal explotación, puede ordenar se mantenga indivisa (art. 1.056-2).

d) Cualquiera de los hijos o descendientes obligados a pagar en metálico la cuota hereditaria puede exigir que dicha cuota sea satisfecha de los bienes de la herencia (art. 842).

Puede colisionar en la práctica el contenido del artículo 842 y el del 1.056-2 con el del 841-1 ya que los dos artículos primeramente citados no exigen que el pago sea con bienes de la herencia, y si bien puede sostenerse que el 841 es complementado por el 842 , y por ende se necesita que el pago en metálico sea procedente de los bienes de la herencia, no sucede lo mismo con el 1.056-2 y si la explotación agrícola industrial o fabril es la fuente de ingresos de la familia puede ser difícil encontrar un metálico suficiente para compensar al resto de los herederos, si es adjudicada exclusivamente a uno de ellos, por lo que no debe propugnarse que en tal hipótesis sea imprescindible el pago con los bienes de la herencia; y ello es tanto o más defendible cuando la aprobación de todos los interesados o la judicial es una garantía adicional del equilibrio de la partición. 
e) Tal partición necesita el consentimiento de todos los herederos o la aprobación judicial (art. 843).

En virtud del principio de respeto a los propios actos, estimo suficiente para que sean válidas las adjudicaciones con pagos en metálico el que el contador-partidor sea autorizado a tal efecto por todos los interesados.

La falta de aprobación de todos los hijos o descendientes puede obviarse por la alternativa de la aprobación judicial (art. 843).

f) Que se comunique a los preceptores en el término de un año desde la apertura de la sucesión (art. 844).

g) Que el pago se haga en el plazo de otro año más, salvo pacto en contrario (art. 844).

h) Todo ello sin perjuicio de que los coherederos se abonen mutuamente las rentas y frutos que cada uno haya percibido de los bienes hereditarios, así como las impresas útiles y necesarias hechas en los mismos y los daños ocasionados por malicia o negligencia (art. 1.063).

En consecuencia el contador-partidor para poder adjudicar a uno de los herederos determinados bienes hereditarios con obligación de pagar en metálico a otros necesitará una clara justificación en las hipótesis antes mencionadas. Tal postura legal tiene una base y fundamento no sólo en que a cada heredero le puede interesar por diversas razones, entre ellas las afectivas, obtener parte de los bienes propiamente hereditarios y no su valor en metálico sino, también, en que se le podría imponer a un heredero una gravosa carga económica que no estuviera en situaciones financieras de hacer frente. Pero estas razones, que son válidas, dificultan la salida de la proindivisión y en determinadas hipótesis no queda mas alternativa al contador-partidor que obtener la confirmación de todos los herederos o efectuar unas ad]udicaciones en proindivisión, con la ulterior solución de terminar la misma mediante acuerdo de las partes o un litigio para poner fin a dicho estado.

¿Las anteriores consideraciones son igualmente apreciables cuando se trata simplemente de complementos en metálico?

La Resolución de la Dirección General de los Registros y del Notariado de 2 de diciembre de $1964^{39}$ señala cómo los contadores-partidores deben atenerse en el cumplimiento de sus obligaciones cuando no se les ha autorizado expresamente por el testador a las normas genéricas del Código Civil, pero en aplicación del 1.062 del Código Civil permite, como excepción, que cuando una cosa es indivisible sea atribuida a uno solo con compensaciones a los demás.

39 Ar. 5.928. 
Tal criterio aun cuando, no corroborado por la jurisprudencia del Tribunal Supremo, parece lógico: hay que, en determinados supuestos interpretar de manera amplia las limitaciones legales ya que de lo contrario, habría innumerables particiones imposibles de efectuar y cuadrar matemáticamente unos lotes en muchos casos es francamente inviable, a no ser que se altere los valores reales de los mismos — lo que no sólo sería injusto, sino ilícito, e incluso delictivo - y el pago en metálico de los bienes de la herencia sólo sería factible si tales bienes se encuentran, por lo que la interpretación amplia buscando un justo equilibrio de los artículos citados del Código Civil parece la única solución posible y justa.

\subsection{Adjudicación para pago de deudas}

¿Cabe la adjudicación en pago de deudas por parte del contador-partidor de los herederos?

Sáenz de Santa María ${ }^{40}$ estudiando la jurisprudencia existente se inclina por la respuesta afirmativa, opinión que también comparten Albaladejo García, Díez Alabart ${ }^{41}$, y Castan Tobeñas ${ }^{42}$ si bien éste expresa la necesidad del consentimiento para ello de los coherederos.

El Tribunal Supremo en Sentencia de 25 de junio de $1946^{43}$ ha entendido que tal adjudicación era válida:

«Que la adjudicación de bienes de una herencia para pago de deudas reconocidas contra la misma, constituye un acto de partición, por virtud del cual y conforme al principio estatuido en el artículo 691 del Código Civil de que cada heredero es responsable de las deudas hereditarias, pueden éstos asignar determinados bienes, a cualquiera de los partícipes en la sucesión, imponiéndole, al propio tiempo la obligación de satisfacerlas con el importe de los bienes adjudicados a tal fin: lo cual presupone, necesariamente, el concurso y la conformidad de todos los interesados en la herencia, ya que reunidos, y no aisladamente, tienen la titularidad del derecho de disposición del patrimonio que la integra.»

El mismo criterio ha mantenido la Dirección General de los Registros y del Notariado en Resolución de 20 de setiembre de $1933^{44}$ si bien señalando que en tal supuesto es condición que los inmuebles adjudicados no salgan del poder de los inmediatamente llamados al patrimonio relictos, porque si se hiciera a extraños se realizaba una enajenación a título oneroso que requeriría el consentimiento de todos los interesados.

\footnotetext{
40 Obra citada, p. 429.

41 Obra citada, p. 251.

42 Derecho Civil Español Común y Foral, tomo VI, vol. I, Madrid 1960, p. 282.

43 Ar. 838.

44 Ar. 276 bis.
} 


\subsection{Liquidación de la sociedad de gananciales}

¿Puede el contador-partidor proceder a la liquidación de la sociedad de gananciales?

Partiendo de la base de que la sociedad de gananciales no está integrada dentro de la masa hereditaria no parece posible entender que el contador-partidor tenga facultades para efectuar la liquidación de la herencia sin anuencia del cónyuge superstite.

Señala Saénz de Santa María ${ }^{45}$ que la solución que se ha impuesto en estos casos es la de proceder a la liquidación de la sociedad de gananciales por el contador-partidor con el concurso o consentimiento del cónyuge superstite.

La solución de efectuar la partición conjuntamente con el cónyuge viudo ha sido, por tanto, aceptada por la doctrina ${ }^{46}$, y por la jurisprudencia ${ }^{47}$.

El Tribunal Supremo ha precisado que no debe confundirse la liquidación de la sociedad de gananciales con la participación de la herencia aun cuando suela coincidir la liquidación con la partición de los bienes de uno y otro de los cónyuges ${ }^{48}$.

Ciertamente puede haber y de hecho cada vez es más frecuente, una liquidación de la sociedad de gananciales sin existencia de herencia: pensemos en los casos de disolución de la misma; en tales hipótesis por esencial, el contador-partidor designado al efecto no necesitará el consentimiento de ninguno de los cónyuges sino simplemente que sea designado a tal fin.

\subsection{Arbitrar las diferencias}

El contador-partidor no es un árbitro, ni tiene las facultades que para el árbitro señala la Ley de Arbitraje de Derecho Privado.

No obstante se puede decir que indirectamente lo es en cuanto en el cuaderno particional pueden y deben solventarse las diferencias que mantengan los herederos siempre que estén dentro del ámbito del respectivo cuaderno particional: por eso no cabe predicar respecto del contador-partidor la necesidad de audiencia de las partes que exige respecto del árbitro o los árbitros el artículo 21 de la Ley 36/88 de Arbitraje.

45 Obra citada, p. 433.

46 Roca SAStre: obra citada, p. 849 y Ruiz Artacho, S.: obra citada, p. 254, si bien éste señala que puede el contador-partidor prescindir del cónyuge si previamente ha liquidado conjuntamente con él la sociedad conyugal.

47 Sentencias 31 de diciembre de 1912 (C.J., tomo 123, n. ${ }^{\circ} 40$ ), 22 de agosto de 1914 (C.J., tomo 131, n. ${ }^{\circ}$ 51), 10 de enero de 1935, Ar. 35 y 17 de abril de 1943, Ar. 418.

48 Sentencia 2 de febrero de 1960, Ar. 175. 
Evidentemente los efectos del arbitraje de acuerdo con la Ley 36/88 de 5 de diciembre y los del cuaderno particional son distintos, y también los requisitos de uno y otro.

En mi opinión lo que sí sería posible es que los herederos, al mismo tiempo que de las suyas, revistieran al contador de las funciones de árbitro suscribiendo para ello un documento al amparo de lo que dispone el artículo 6 de la Ley 36/88, aunque tal imposición por parte del testador podría no ser válida.

\section{Efectos}

\subsection{Ejercicio de la partición}

El contador partidor deberá realizar la partición en el plazo fijado: tengamos en cuenta que el nombramiento del contador-partidor produce el efecto de que los herederos no pueden distribuir la herencia mientras esté vigente el plazo señalado al mismo ${ }^{49}$. Ahora bien, los albaceas deben cumplir su encargo en el plazo fijado por el testador y si no en el de un año, ya que de no hacerlo así caducaran sus funciones ${ }^{50}$ teniendo por tanto los herederos libertad para proceder como estimaran conveniente.

La emisión del cuaderno particional por el contador-partidor - o por el contador-partidor y el cónyuge superstite en los casos en que sea necesario- pone fin con su protocolización e inscripción en el registro de la propiedad correspondiente a las operaciones testamentarias.

\subsection{Forma}

En cuanto a la forma, si bien la Ley no impone forma alguna para la partición dado que en la misma se da en la mayoría de los casos el título para las adjudicaciones concretas deberá constar en documento público, el cual será o la escritura notarial a la cual quede incorporada la aprobación judicial de la misma en los supuestos de juicio de testamentaría o de abintestato.

$\mathrm{Si}$ es por medio de notario podrá ser mediante comparecencia o por entrega del cuaderno particional ya formalizado, podrá acogerse a la forma de acta o de escritura.

49 Sentencia 22 de enero de 1952, Ar. 46. MenÉNDEZ-VALDÉs GolPE: «¿Pueden partir los herederos habiendo contador-partidor?» en $R D N$, enero-marzo 1970, pp. 155 y ss., entiende que sí pueden efectuarlo siempre que se adelanten a la partición del contador y, en cualquier caso, que podrán hacer las permutas, cesiones, etc. que estimen convenientes.

50 Sentencia 16 de febrero de 1977, Ar. 368. 
De acuerdo con una reiterada jurisprudencia la partición no requiere el consentimiento de los interesados ${ }^{51}$, criterio compartido también por la jurisprudencia registral, si bien ésta ha manifestado que tal falta de consentimiento de los interesados sólo opera en tanto en cuanto no sea rescindida la partición ${ }^{52}$; todo ello en base a que las actuaciones del contador-partidor son de carácter unilateral ${ }^{53}$.

Sin embargo la anterior premisa quiebra cuando existan menores o sujetos a tutela porque el principio de que la partición no necesita el consentimiento de los interesados sólo se produce en los supuestos en que no hubiera menores o sujetos a tutela ${ }^{54}$.

En cambio si se trata del contador-partidor dirimente deberá entregar el cuaderno particional ante el juzgado y con ello los trámites de partición no terminarán ya que se pondrá de manifiesto a las partes (art. 1.079 L.E.C.) pudiendo presentarse oposición en el término de ocho días por cualquiera de ellos, y si no hay tal oposición el juez aprobará sin más el cuaderno particional (art. 1.083 L.E.C.) mientras que cuando hubiera oposición se le entregan los autos a la parte que lo anuncie por el término de quince días en los cuales, si no se formalizara de nuevo la oposición, se aprobará la partición (art. 1.085 L.E.C.) y si se presentare ésta se le dará el trámite del juicio ordinario que por su cuantía corresponda (art. 1.088 L.E.C.).

¿Agota la partición la emisión del cuaderno particional?

El Tribunal Supremo ha admitido que el contador-partidor formule una complementaria para determinar extremos relativos a bienes no comprendidos en la anterior, en la Sentencia de 3 de enero de $1967^{55}$, si bien como principio parte la sentencia citada de que las funciones del comisario se agotan cuando se cumpla el plazo previsto o cuando se ultiman las operaciones particionales, debiendo, si no se está en tales supuestos las partes autorizar al contador-partidor para la nueva actuación. En definitiva la posible rectificación del contador-partidor debe ser siempre dentro del plazo conferido.

Es de resaltar que nada impide si aparecieren nuevos bienes una vez terminadas las operaciones particionales el nombramiento de uno o unos nuevos contadores-partidores.

El cuaderno particional contendrá las adjudicaciones concretas que será el título suficiente, a todos los efectos jurídicos, a la adquisición de los bienes adjudicados por parte de los herederos y legatarios.

\footnotetext{
51 Sentencias 17 de junio de 1963, Ar. 3.330 y 18 de febrero de 1987, Ar. 715.

52 R.D.G.D. de 27 de febrero de 1982, Ar. 838.

53 Sentencia 6 de abril de 1962, Ar. 1.712.

${ }^{54}$ Sentencias de 12 de noviembre de 1930, Ar. 82, 15 de octubre de 1957, Ar. 3.007, 23 de diciembre de 1976, Ar. 5.578 y 17 de diciembre de 1988, Ar. 9.475.

55 Ar. 265.
} 


\subsection{Efectos jurídicos}

El artículo 1.068 del Código Civil es tajante sobre el particular al senalar que la partición legalmente confiere a cada heredero la propiedad exclusiva de los bienes adjudicados, y como ha puesto de relieve el Tribunal Supremo una vez practicada la partición el derecho abstracto sobre el patrimonio relecto de los herederos se convierte en un derecho concreto sobre los bienes que a cada heredero le hayan sido adjudicados ${ }^{56}$ todo ello sin perjuicio de la posible evicción al cual están obligados los herederos ex-artículo 1.069 del Código Civil.

La jurisprudencia ha entendido que en principio debe concederse una presunción de legalidad a la partición para evitar que se anulen o rescindan y en ese sentido se ha pronunciado de manera reiterada el Tribunal Supremo ${ }^{57}$.

\subsection{Impugnación}

Nuestro ordenamiento es reticente a la hora de impugnar las particiones efectuadas, habiendo precisado el Tribunal Supremo en la Sentencia de 15 de junio de $1982^{58}$ :

«El Código Civil carece casi en absoluto, de normas relativas a la nulidad de las particiones hereditarias, lo que confirma el propio recurso, al no citar en este punto, como infringido, ningún precepto legal, sino sólo la indicada doctrina jurisprudencial, olvidando que ésta, a partir de las sentencias de 25 marzo 1914 y 7 enero 1932, afirmó la necesidad de respetar el criterio de nuestro ordenamiento jurídico, muy restrictivo en cuanto a la admisión de las pretensiones de invalidez de las particiones "como se deduce de los arts. 1.079, 1.080, 1.056 y 1.057 del Código Civil", en el sentido de no dar lugar a la invalidez sino cuando no haya más remedio, para evitar la vuelta de los bienes a la indivisión y los gastos, molestias e inconvenientes que acarrearía una nueva partición, doctrina que se confirmó en las sentencias de 17 de abril 1943, 9 marzo 1951, 17 marzo y 5 noviembre 1955, 30 abril 1958 y 25 febrero 1969, entre otras; añadiéndose, además, que cuando la partición tenga naturaleza de contrato -que es el supuesto que se contempla en que fue hecha por los interesados de común acuerdo- habrá de serle aplicable el derecho común de los contratos, con la consiguiente distinción entre nulidad absoluta o

56 Sentencia 21 de julio de 1986, Ar. 4.575, en análogo sentido en cuanto al carácter determinativo o especificativo de derechos que confiere la partición, sentencias de 6 de mayo de 1958, Ar. 1.719, 29 de mayo de 1963, Ar. 3.589 y 27 de noviembre de 1972, Ar. 4.663.

57 Sentencia 30 de abril de 1958, Ar. 1.698, 13 de octubre de 1960, Ar. 3.085, 25 de febrero de 1969, Ar. 999, y 14 de febrero de 1985, Ar. 553.

58 Ar. 3.428. 
radical y anulabilidad o nulidad relativa, rigiendo para la segunda lo establecido en los artículos 1.300 al 1.314 —sentencias de 26 marzo 1940, 7 enero 1949, 9 marzo 1951, 2 noviembre 1957, 29 marzo 1958, 13 octubre 1960, 25 noviembre 1965, 25 febrero 1966, 26 noviembre 1974, y 7 enero 1975 entre otras-, con el prescriptivo plazo de cuatro años que para la acción establece el artículo 1.301.»

De la sentencia transcrita se deduce no sólo la postura jurisprudencial contraria a la impugnación de la actuación de los contadores partidores siempre que ello sea posible sino, también, que el Tribunal Supremo cuando alude a impugnación se refiere fundamentalmente a las acciones de nulidad y de rescisión.

Por eso hay que distinguir en cuanto a las posibilidades de combatir una partición efectuada por un contador-partidor entre que éste actúe como dirimente dentro del procedimiento de abintestato o testamentaría de si es dativo o designado por el testador.

En la primera hipótesis las posibilidades de combatir la actuación del contador-partidor vendrán en base a la impugnación en los términos señalados previamente, con el efecto de conseguir que el juez no apruebe el cuaderno particional, ya que como señala Soto Nieto ${ }^{59}$ la falta de oposición supone una conformidad tácita en la misma y, en definitiva, dan origen a su aprobación. Por eso la oposición deberá tener como consecuencia casi ineludible — salvo el supuesto de conformidad de todas las partes en la junta que señala el artículo 1.086 de la Ley de Enjuiciamiento Civil- el ejercicio del juicio declarativo correspondiente conforme a lo que se acaba de exponer, juicio que como resalta Soto Nieto ${ }^{60} \ll$ no ha de considerarse como un punto y aparte del juicio testamentario, sino como un estadio eventual del mismo».

Cuando aludimos al contador partidor dativo o al designado por el testador no cabría los trámites señalados, que están previstos específicamente en la Ley de Enjuiciamiento Civil para el contador-partidor dirimente, con lo cual, las posibilidades de impugnación quedarían limitadas a las acciones de nulidad y rescisión que contienen el Código Civil.

Todo ello sin perjuicio de que se pudiera promover un juicio declarativo específico en reivindicación de determinados bienes hereditarios.

El Código Civil contiene la posibilidad de rescisión de las particiones cuando exista lesión en una cuarta parte del valor de las cosas aseguradas, de acuerdo con el artículo 1.074 del Código Civil, habiendo

59 «Juicio de testamentaría», en Cuestiones jurídicas (jurisprudencia creadora), Madrid 1976, tomo III, p. 425.

60 Obra citada, p. 430. 
puesto de relieve la doctrina ${ }^{61}$ la necesidad de la lesión de la cuarta parte para que pueda rescindirse la partición, de acuerdo con la acción específica que para ello contiene el Código Civil.

El Tribunal Supremo ha precisado que para la aplicación del artículo 1.074 del Código Civil se necesita que exista un perjuicio a la lesión máxima tolerable ya que se trata de una norma específica en materia de rescisión, debiéndose referirse la lesión de la cuarta parte al valor al tiempo de la adjudicación y no al de la abertura de la sucesión ${ }^{62}$ y en concreto al del total del lote adjudicado ${ }^{63}$.

El que la partición se haya efectuado en juicio de testamentaría por el contador partidor dirimente no impide que pueda ejercitarse ulteriormente las acciones de rescisión de la herencia, aún cuando hubiera aprobación judicial, según ha señalado el Tribunal Supremo en Sentencia de 7 de febrero de $1969^{64}$.

Independientemente de las acciones de rescisión estarán las acciones de nulidad, debiéndose distinguir, incluso, entre las particiones radicalmente nulas y las anulables ${ }^{65}$. Ahora bien, como la aplicación de la teoría de la nulidad es en base a entender que la partición tiene naturaleza de contrato ${ }^{66}$ parece difícil aplicar los supuestos de nulidad de contrato a la actuación del contador-partidor por lo que, en tal hipótesis, sólo quedaría el ejercicio de los medios de impugnación reconocidos en la Ley de Enjuiciamiento Civil cuando se trate de contador-partidor dirimente, más la posibilidad de la rescisión por lesión; y cuando se tratara de contador-partidor dativo la pertinencia exclusivamente de las acciones de resolución.

\section{Bibliografía sumaria}

Albaladejo: «Dos aspectos de la partición hecha por el testador», en Anuario de Derecho Civil, 1948.

Albaladejo y Díaz Alabart, S.: Comentarios al Código Civil y compilaciones forales, tomo XXI, vol. II.

CAMY SÁNCHEZ-CAÑETE, B.: «Contador-partidor y personas a quienes válidamente puede adjudicar bienes», en Revista de Derecho Privado (1968).

61 AlbaladeJo: «Dos aspectos de la partición hecha por el testador», en Anuario de Derecho Civil, 1948, p. 964.

62 Sentencia 19 de diciembre de 1967, Ar. 255 de 1968.

63 Sentencia 17 de enero de 1985, Ar. 181.

64 Ar. 652.

65 Sentencia 7 de enero de 1975, Ar. 12.

66 Sentencia 15 de junio de 1982, Ar. 3.428. 
Castán ToBeñas: Derecho Civil Español Común y Foral, tomo VI, vol. I, Madrid 1960.

DíEz Picazo y Gullón: Instituciones de Derecho Civil, vol. II, Ed. Tecnos, Madrid 1995.

ESCOBAR DE LA RIVA: «Partición por comisario», en Revista Crítica de Derecho Inmobiliario, 1940.

García Monje, M.: «La partición de la herencia», en Revista de Derecho Privado, 1954

LaCRUZ Verdejo y Sancho Rebullida: «Elemento de Derecho Civil», tomo V, en Derecho de Sucesiones, Barcelona 1981.

Lledó Yagüe, F.: Derecho de sucesiones, vol. II a IV, Universidad de Deusto-Bilbao, 1991-1993.

MENÉNDEZ-VALdÉs GolPE: «¿Pueden partir los herederos habiendo contador partidor?», en $R D N$, enero a marzo 1970, pp. 155 y ss.

PUig Ferriol: El albaceazgo, Ed. Boch, Barcelona 1967.

Roca SASTRE: Derecho hipotecario, tomo III, Barcelona 1968.

RodRíGUEZ AdRADOS, S.: «La partición hecha por el testador», en Revista de Derecho Notarial, abril-junio 1970.

RuIz ARTACHO, S.: «Partición de herencia por comisario», en RCDI de 1952.

SÁENZ DE SANTA María Tinture, I.: «Notas sobre los albaceas y contadores-partidores», en Anuario de Derecho Civil, VI-2 (1953).

Soto NiETO: «Juicio de testamentaría», en Cuestiones jurídicas (jurisprudencia creadora), Madrid 1976, tomo III.

TortosA, A.: «Contador-partidor dativo», en Boletín Informativo Colegio Notarial de Granada, n. ${ }^{\circ}$ 13, enero 1982.

VALLET DE GOITISOLO: «Facultades de los contadores-partidores para interpretar el testamento», en Anuario de Derecho Civil, 1965. 